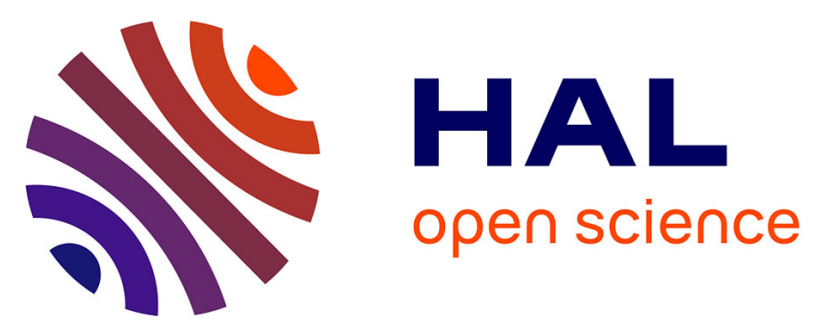

\title{
Using Games to Build and Improve 10th Grade Students' Understanding of the Concept of Chemical Bonding and the Representation of Molecules
}

Karine Molvinger, Gaëtan Lautier, Rose-Marie Ayral

\section{To cite this version:}

Karine Molvinger, Gaëtan Lautier, Rose-Marie Ayral. Using Games to Build and Improve 10th Grade Students' Understanding of the Concept of Chemical Bonding and the Representation of Molecules. Journal of Chemical Education, 2021, 98 (2), pp.319 - 329. 10.1021/acs.jchemed.0c01287 . hal03169786

\section{HAL Id: hal-03169786 \\ https://cnrs.hal.science/hal-03169786}

Submitted on 17 Mar 2021

HAL is a multi-disciplinary open access archive for the deposit and dissemination of scientific research documents, whether they are published or not. The documents may come from teaching and research institutions in France or abroad, or from public or private research centers.
L'archive ouverte pluridisciplinaire HAL, est destinée au dépôt et à la diffusion de documents scientifiques de niveau recherche, publiés ou non, émanant des établissements d'enseignement et de recherche français ou étrangers, des laboratoires publics ou privés. 


\title{
Using games to build and improve $10^{\text {th }}$ Grade students' understanding of the concept of chemical bonding and the representation of molecules.
}

\author{
Karine Molvinger*, Gaëtan Lautier and Rose-Marie Ayral
}

Institut Charles Gerhardt Montpellier, Univ Montpellier, CNRS, ENSCM, Montpellier, France

\begin{abstract}
This article focusses on the case study around the concept of covalent bonding for 10th Grade pupils in France. Based on their conceptions and difficulties, a didactical engineering has been established that should lead to improvement of understanding of this concept. After analysing the pupils' difficulties, we reflected on the construction of the concept of bonding as it is introduced in 10th Grade. We argue that the use of several semiotic registers can promote the assimilation of the concept of covalent bonding. The results show that an approach based on learning games allows pupils to take an active part in the construction of the covalent bonding concept and that the stability of this construction depends greatly on the semiotic registers mobilized.
\end{abstract}

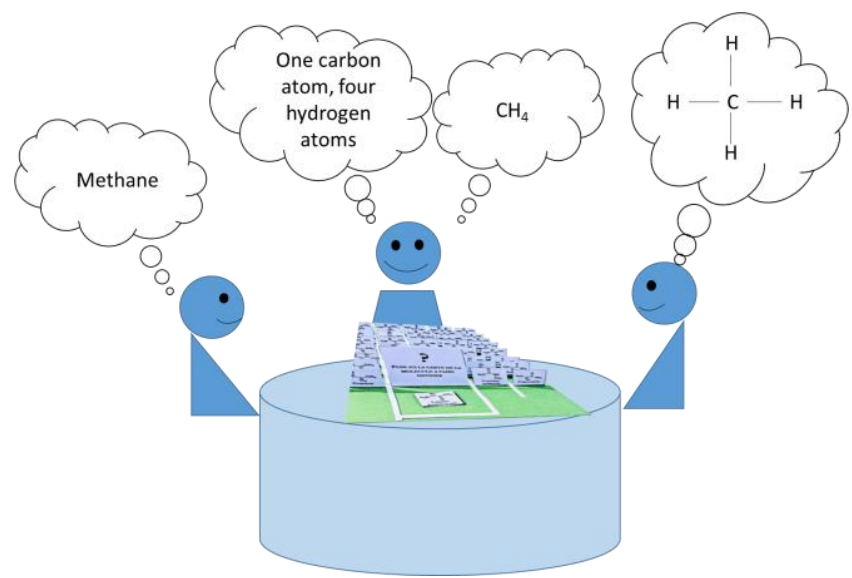

\section{KEYWORDS}

High school, Chemical Education Research, Collaborative/cooperative learning, games, covalent

bonding.

\section{INTRODUCTION}

Organic chemistry is a difficult subject for pupils because it is based on a high level of formalism, whether for the representation of the molecules or for that of the process of a chemical reaction. ${ }^{1}$ This branch of chemistry is introduced, in France, in $10^{\text {th }}$ Grade (15-16 years old), using the model of the covalent bond, then in $11^{\text {th }}$ Grade (16-17 years old), using the Lewis model. The pupils are then exposed to the representation of the molecules and brought to assess the sharing of electrons between two atoms of a bond. As a result, they are able to determine whether a site is deficient in or enriched with electrons, and are therefore able to interpret the reactivity of simple organic molecules. This method of describing reactivity is limited and the results of certain reactions cannot be interpreted in this traditional way. ${ }^{2,3}$ For example, the selectivity properties of the Diels Alder reaction cannot be justified by the traditional model taught in high school. This is why, in higher education, 
the students are presented with a new way of interpreting the reactivity of organic molecules. This involves using the theory of orbital boundaries to justify the results of certain reactions. In other words, the students are required to grasp a new model of chemical bonding, which relies on the probabilistic nature of the electron and the orbital aspect of the chemical bond. The bond is no longer characterized by a line but by molecular orbitals. This transition from the traditional model to the orbital model raises many questions among the students. ${ }^{4}$ In particular, the work of Lautier showed that some did not establish a link between these two models and that they were not aware of the limits of each theory. ${ }^{5}$ It is therefore essential to work from the moment the traditional covalent bonding model is introduced, on the concept of the model and its limits. The challenge is then to make these aspects more intuitive to $10^{\text {th }}$ Grade pupils, without addressing the elements of the orbital model that are not in the official $10^{\text {th }}$ Grade curriculum. ${ }^{6}$

In this work, we identified the pupils' difficulties associated with the way the concept of covalent bonding and the representations of molecules are taught. A didactical engineering process, based on board games, was set up and its analysis enabled the effectiveness of this teaching sequence to be assessed. Once experimented in $10^{\text {th }}$ Grade class in particular, it was possible to analyze to what extent this didactical engineering facilitated the learning of the bond concept.

In a first part, we discuss official instructions and information on the subject available in works published on pupils' difficulties. This background allows us, in a second part, to set the objectives of the research and then to specify the theoretical framework. Then, the methodology is addressed with an explanation of the didactical engineering, the corpus with the description and explanation of the board games and tests. The results are therefore discussed in two parts: the qualitative analysis of the games and the quantitative analysis of the tests we have developed, which allow us to evaluate the effectiveness of the sequence.

\section{BACKGROUND}

Instructions in France $\left(10^{\text {th }}\right.$ Grade)

In France, the covalent bond is defined as the sharing of two external electrons by and between two atoms, each atom bringing an electron (Figure 1). It is specified that in the structural formulae, they are represented whereas in the semi-structural formulae ${ }^{7}$, the bonds concerning hydrogen are not. Pupils manipulate molecular models where bonds are represented by lines in the case of exploded models. The definition of isomers is also discussed. In addition, the model of the atom, its constitution as well as that of its nucleus and the distribution of the electrons in different layers are studied. The octet (and duet) rule is taught. The octet rule is a chemical rule of thumb that reflects the observation that elements tend to bond in such a way that each atom has eight electrons in its valence shell, giving it the same electronic configuration as a noble gas (duet rule for hydrogen).

Shared electrons: 8 electrons in valence shell of each $\mathrm{Cl}$ atom

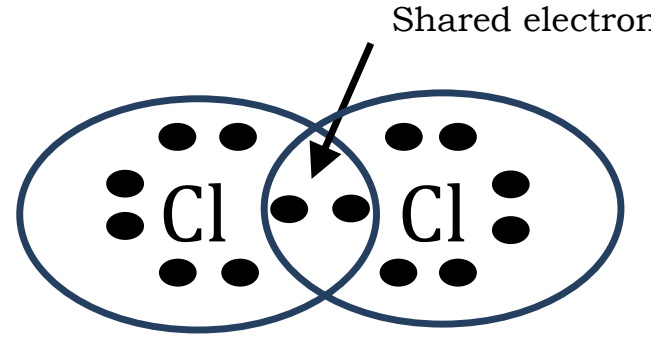

Figure 1: Representation of the covalent bond between two $\mathrm{Cl}$ atoms

Then, the bond within a molecule is represented by two dots symbolizing the shared electrons.

\section{Students' conceptions}

This part aims to describe the alternative or erroneous conceptions that may exist among $10^{\text {th }}$

Grade pupils related to the covalent bond. First, some of these conceptions result from a misunderstanding of concepts previously studied by the pupils. For example, Taber evokes the common misconception that atoms would be the basic unit of matter, which they call "the building block". 8 In other words, during his work, he realized that some pupils do not perceive any 
contradiction in asserting at the same time that "atoms are made up of protons, neutrons and electrons" and that "the atom is the basic component of matter" and interlocks with other atoms to form molecules. Therefore, for these pupils, a molecule is an assembly of atoms combined like a LEGO® game.

From this first erroneous conception follows a second, which corresponds to a partial understanding of the chemical bond. Indeed, the covalent bond being a sharing of two electrons, it would be considered as an attachment between the two atoms. In other words, one could compare the sharing of the electrons of two atoms with the act of hanging two objects together. In particular, Wightman et al. found that pupils have difficulty conceiving the chemical bond as an electromagnetic interaction and that they compensate for this difficulty by considering the bond between atoms as a material one. 9 The authors note in particular certain conceptions such as the fact that atoms are associated by interlocking shapes or that they are retained by "a kind of string". This materialist conception runs counter to the notion of the stability of a molecular edifice and could lead to several difficulties in the study of chemical reactions involving formations and breaks in chemical bonds.

In their article, Unal et al. propose a mapping of the different conceptions of the students concerning the chemical bond. ${ }^{10}$ In particular, they highlight the following conceptions:

- The electrons would be negatively charged ions and the chemical bond would form between them. A limited understanding of the microscopic description of the matter is observed since these pupils do not seem to distinguish between the notions of chemical species and electron. This description suggests that the chemical bond forms between the electrons instead of understanding that the electrons constitute the chemical bond.

- Within the chemical bond, the electrons do not move. Some pupils even say that the electrons of the bond "sit between the nuclei". This confusion probably arises from the representation of the covalent bond as a stick fixed between two atoms. This idea completes that of a physical and material link between the atoms forming a bond. However, this idea is consistent with the Lewis model taught where electrons are represented by fixed lines.

In their study, Peterson and Treagust highlight the difficulties that pupils have in establishing the structures of molecules. ${ }^{11}$ More particularly, they evoke an initial conception according to which, for the pupils, the atoms form as many covalent bonds as there are electrons on their valence layer. They use the example of the nitrogen atom, which, for some pupils, should form five bonds within a molecule since this element has five valence electrons. This vision stems from a misunderstanding of the octet rule. For Robinson, however, abandoning the octet rule is not a solution. ${ }^{12}$ On the other hand, it should be emphasized that this rule is above all a tool for recognizing stable structures and that the filling of the layers is only a consequence of the way the bonding is formed, and not the opposite. ${ }^{13}$

Two other points should be mentioned. Another more recent review points to the fact that the simplification of the models of bonding representation in textbooks leads to misconceptions among students. ${ }^{14}$ Taber and Watts also point out that there are many pupils who personify atoms and use the verbs "will" or "need" to describe the phenomena in which atoms interact. ${ }^{15}$

There are other misconceptions around the chemical bond. However, they are related to the geometrical structure of molecules, to the repulsions of non-bonding electron pairs, to the polarity of molecules, or else to the electronegativity of elements - so many notions that are not in the $10^{\text {th }}$ Grade curriculum and which, consequently, are not exposed here.

\section{RESEARCH AIMS AND THEORETICAL FRAMEWORK}

This work focuses on the effectiveness of a chemistry instructional intervention for pupil learning. The aim of this work is to see whether teaching in the form of games can lead to a better understanding of these notions. The analysis focuses on the importance of language and the representations systems in learning scientific concepts such as chemical bonding. The chosen theoretical framework uses tools derived from semiotics. In order to conceptualize the chemical bond, it is possible to use various types of representations: diagrams, sentences, graphs like curves of electronic isodensity, mathematical calculations, etc. Duval distinguishes mental representations, which constitute the set of conceptions possessed by a learner on an object, from semiotic representations, which correspond to the set of objects using the same signs and belonging to the same system. ${ }^{16,17}$ More particularly, these semiotic representations are communication tools used to 
make mental representations explicit to others. According to Duval ${ }^{18}$, who set up this theoretical framework for mathematics, a semiotic system must allow three cognitive activities inherent to all representations to be carried out:

- The setting up of an identifiable representation allows the use of a set of identifiable characters of the object to be represented which can be recognized and which complies with the rules specific to this system of representation.

- The processing of a representation consists in transforming this representation into its own register by respecting the rules of the register, so as to obtain other representations that can constitute additional knowledge compared to the initial representations. Duval speaks of internal transformation in the initial register.

- Conversion allows the representations produced in one system to be converted into representations of another system in such a way that the latter allows other meanings relative to what is represented to be explained. It is then a transformation external to the initial register.

Any semiotic system that satisfies the criteria for these three activities is called a semiotic representation register or simply a semiotic register. Duval explains that each register implies "a selection of the significant or informational elements of the content that one represents", which means that the registers do not implement the same aspects of a concept.

The interest inherent in a coordination of several registers in a learning process is thus to enrich the studied concept to facilitate comprehension. According to Duval, among the three cognitive activities, only the training and treatment aspects are properly taken into account in teaching, thus causing a partitioning of the representation registers. The understanding of a concept through a single register limits the ability of the pupil to mobilize this concept in various situations and reduces some of the meaning given to it. Indeed, in the sense of Duval, Malonga Moungabio and Beaufils represent a concept using different registers ${ }^{19}$ :

- The register of natural language, corresponding to the written word;

- The register of common language, corresponding to speaking;

- The numerical register consisting of tables of empirical or calculated values;

- The formal register constructed from algebraic expressions;

- The graphic register organized around the various curves obtained experimentally or not;

- The illustrated register which includes all the diagrams allowing access to the concept.

Figure 2 shows an adaptation of the different registers proposed by Duval for the concept of covalent bonding.

\begin{tabular}{|c|c|c|c|c|}
\hline Register of natural language & \multicolumn{4}{|c|}{$\begin{array}{l}\text { The covalent bond corresponds to } \\
\text { the sharing of two electrons }\end{array}$} \\
\hline Formal or algebraic register & \multicolumn{4}{|c|}{$\begin{array}{l}\text { For octet: } \mathrm{N} \text { ( bonds) }=8-\mathrm{p} \text { where } \mathrm{p} \\
\text { is the number of valence electrons }\end{array}$} \\
\hline \multirow[t]{3}{*}{ Numerical register } & Atom & $\mathrm{H}$ & $\mathrm{C}$ & $\mathrm{Cl}$ \\
\hline & $\begin{array}{l}\text { Number of } \\
\text { external } \\
\text { electrons }\end{array}$ & 1 & 4 & 7 \\
\hline & $\begin{array}{l}\begin{array}{l}\text { Number of } \\
\text { bonds }\end{array} \\
\end{array}$ & 1 & 4 & 1 \\
\hline Graphic register & \multicolumn{4}{|c|}{$\begin{array}{l}\text { Energy representation, energy } \\
\text { diagram of molecular orbital, electron } \\
\text { density (not applicable at this level of } \\
\text { education) }\end{array}$} \\
\hline Illustrated register & \multicolumn{4}{|c|}{$\mathrm{Cl} \stackrel{\mathrm{O}}{\mathrm{C}}$} \\
\hline
\end{tabular}


This representation of the covalent bond in various semiotic registers thus enriches its conceptualization. It is important to note that each of these registers highlights different properties of the concept. Other researchers have adopted this theoretical framework in mathematics ${ }^{20,21}$ but also in chemistry 22 thus proving that it is adapted to subjects other than mathematics.

The lesson plan on the representation of the molecules mainly uses the semiotic registers of natural language, schema and photography. There are also some subtasks using the equation register. This is why we have chosen to focus this study on the impact of semiotic registers of diagram and natural language on the effectiveness of the lesson plan.

The aim of the study is to show that teaching that brings into play several semiotic registers would allow a better understanding of the concept of chemical bonding. Coordinating semiotic registers is not spontaneous, it seems important to focus on training sessions allowing conversion activities between the registers. Converting a representation from one system to another allows other aspects of the concept to be explained and extends understanding. This type of teaching would allow the difficulties related to representations of the concept of bonding to be taken in hand. In summary, our research question is whether the mobilization of several semiotic registers, through the use of games, allows a better understanding of the concepts of bonding and representation of molecules.

\section{METHODOLOGY}

\section{Didactical engineering}

Didactical engineering can be defined by the design and experimentation of teaching sequences, adopting an internal mode of validation based on the comparison between $a$ priori and $a$ posteriori analysis within the framework of the theory of didactical situations. ${ }^{23}$ It includes four steps:

(i) preliminary analyses investigating the epistemological, cognitive and institutional conditions and constraints;

(ii) design and a priori analysis;

(iii) experimentation;

(iv) a posteriori analysis and validation of the hypotheses underlying the design.

Didactical engineering, as described by Artigue in her founding article, provides a methodology to enable these theories to be put into practice in the classroom. ${ }^{24,25}$ The term "didactical engineering" was introduced in mathematics education by French researchers in the early eighties inspired by the theory of didactical situations. ${ }^{26}$ Didactical engineering became then a privileged methodology of research within this community. "Compared with other types of research based on class experiments, the methodology of didactical engineering is also characterized by the register in which it is placed and the methods of validation used. [...] (It situates) in a case study mode where validation is essentially internal, founded on the confrontation between a priori and a posteriori analysis". ${ }^{27}$ The term was then used in various scientific domains other than mathematics, ${ }^{28}$ in physics ${ }^{29}$ and in chemistry ${ }^{22}$. The links of such constructions with the theory of didactical situations are more or less strong, even if globally these designs tend to optimize the responsibility of students through adidactical ${ }^{30}$ interaction with an appropriate "milieu". ${ }^{31}$

210 Teaching context

We set up, in close collaboration with the teacher, a didactical engineering event based on the use of games that allows the mobilization of several semiotic registers, which should lead to a better understanding of the notion of bonding and of the representation of molecules. The study took place in France. The teacher had completed a master in teaching two years before this study. ${ }^{32}$ This teacher had two $10^{\text {th }}$ Grade classes. There were 36 pupils in each class, none of whom had to retake a year, and were between 14 and 16 years old. Both classes had a very good scientific level. One of the two classes had an overall average of $14.90 / 20$ and a chemistry average of $16.66 / 20$ in the first quarter 
(before the study). The other class had an overall average of 14.10/20 and an average of 14.63/20 in chemistry in the first quarter. For ethical considerations, we distributed an authorization to parents to film their children since they were minors. In it, we explained that we were carrying out research work, that the recordings and questionnaires would be only used for scientific purposes. The publication of the results of this work would respect the strictest anonymity of the persons and places concerned. A parent refused, so we placed the student off-camera.

Data corpus

The corpus of this research consists of videos of the didactical engineering, which have been transcribed. One camera with a microphone was focused on the teacher and another on a group of students. All the words (of the teacher and the students) were transcribed without any elimination from us. The babbling was kept. Here, we use these transcripts to illustrate the analysis of the games; we give some comments from students as they play. We also had access to the students' written traces during the didactical engineering as well as to the assessment made by the teacher at the end of the lesson plan.

Finally, the tests done in class at the beginning (pre-test) and at the end of the sessions (posttest) were useful to interpret the interest of using games. These tests, described just below, were designed by us (chemical education researchers and teacher), each item was devised with the aim of retrieving information for our research questions. The tests were approved by two others teachers who checked that the students could answer them. They also gave them to some pupils who were not involved in the study to ensure that the questions were well understood. The expertise of the developers and the peer approval allow us to guarantee the validity of the tests. These tests were also completed by another $10^{\text {th }}$ Grade class in the same high school, of an equivalent level, but who did not follow the didactical engineering, the rest of the sessions in the lesson plan being similar (control class). We chose this class because its results were similar to the classes tested (overall average: 14.50 and a chemistry average of 15.25) and the results of the pretest are similar: $56 \%$ correct answers for the control class versus $54 \%$ correct answers for the tested classes.

The year following this experiment, a test was administered to $11^{\text {th }}$ Grade pupils at the same high school at the end of the chapter on the Lewis representation. This test took up again the questions from the $10^{\text {th }}$ Grade post-test and was supplemented following the $11^{\text {th }}$ Grade lesson plan. Two teachers A and B administered these tests in three classes (two classes for A and one class for B) taking some time from their chemistry classes. Therefore, among the 82 pupils who took these tests, we can distinguish two populations, one that had followed didactical engineering the previous year (24 pupils) and one that had not (58 pupils). A comparison can therefore be established between these two populations. These $11^{\text {th }}$ Grade pupils did not have the $10^{\text {th }}$ Grade teacher.

\section{Description of the games}

First of all, it is necessary to bear in mind that the section of the $10^{\text {th }}$ Grade curriculum which concerns us, consists of the octet rule, the covalent bond, the different representations of the molecules, the isomerism that were taught just before the didactical engineering. A didactical engineering based on games thus mobilizing different semiotic registers has been set up. From the point of view of the semiotic registers, the coordination of several semiotic registers has been selected to promote the conversion activities between the different representations of the concept of the chemical bond: the register of natural language, that is to say, the written language but also the numerical register, through the use of data tables, then the illustrated register with the use of molecular models and structural formulae.

The focus of this article is this didactical engineering, which involves engaging the pupils in the conversion processes of representations. It is based on games, inspired by well-known board games like "Who is it?" The "Happy Families" game and "Memory". Each game has been designed in order to bring out several registers so that the pupils practise moving from one register to another. Indeed, according to our research hypotheses, this conversion process should enable them to better construct the concepts discussed. Half of the class worked during a one and a half-hour session. The pupils worked in groups of three and had thirty minutes for each game (See Supporting Information for the rules of the game). 
"Happy Families" is organized in such a way that each family has six cards, like in the classic version. It is therefore made up of forty-two cards. Figure 3 shows the methane family. Each card corresponds to a representation or a characteristic of the molecule-family:

- The molecular formula,

- The structural formula,

- The molecular model,

- The chemical function,

- The number of carbon atoms,

- The number of heteroelements.

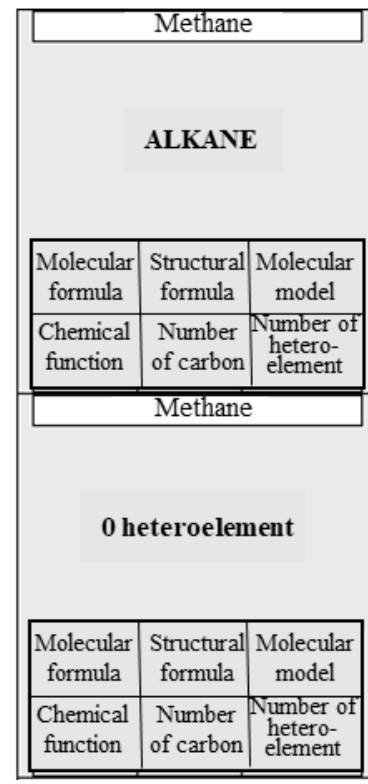

Figure 3: The methane family

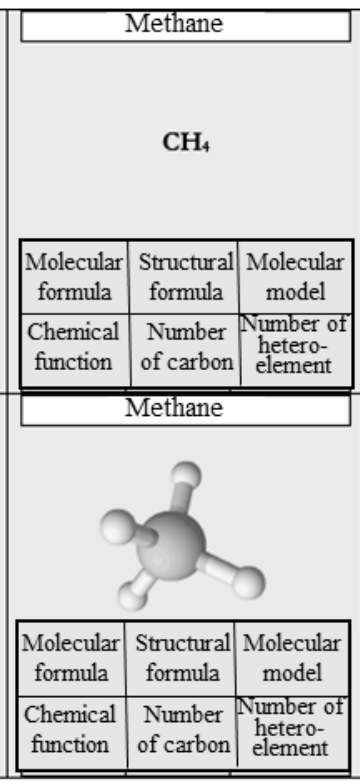

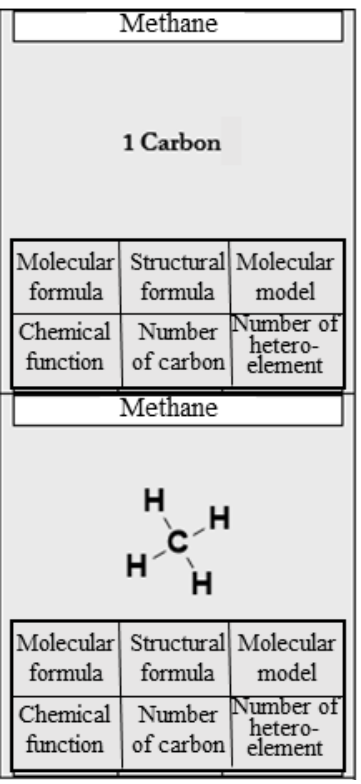

The interest of this game is, above all, to allow the pupils to become actively involved through a game. The second objective of "Happy Families" is to encourage the use by the pupils of different registers: oral through interactions within the group, written through the use of cards, illustrated via the various representations of the molecules and algebraic by counting the carbon and heteroelements present in the molecules.

The "Memory Game" is an adaptation of the traditional game. The cards are placed face down. The change that has been made is the following: instead of having to find two identical cards, it is necessary to find the structural or semi-structural formula and the associated molecular formula. There is a set of twenty-four cards, four of which are presented below (two pairs) (Figure 4).

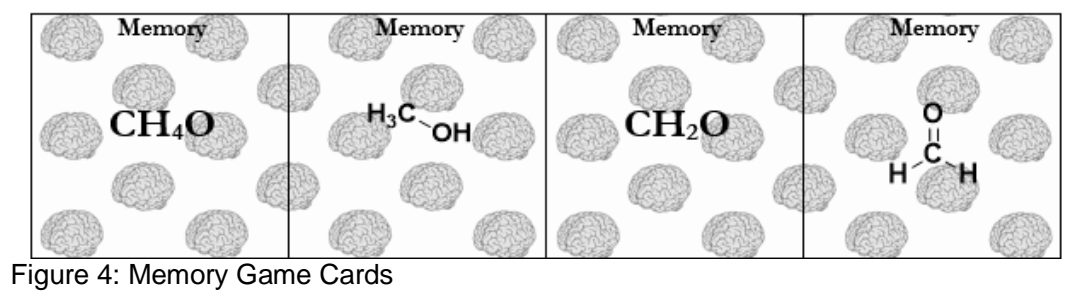

To win, the pupils have to move quickly from the molecular formula to the structural formula and must make use of their memory. This activity brings in the illustrated register but also the algebraic one since the enumeration of the atoms that make up the molecules must be carried out. It should be noted that all the molecules chosen do not constitute isomers in order not to add any difficulties in the activity. 
The game "Who is it?" is inspired by the trade game of the same name. The support used consists of a board (Figure 5) and a deck of cards that corresponds to the different boxes on the board.

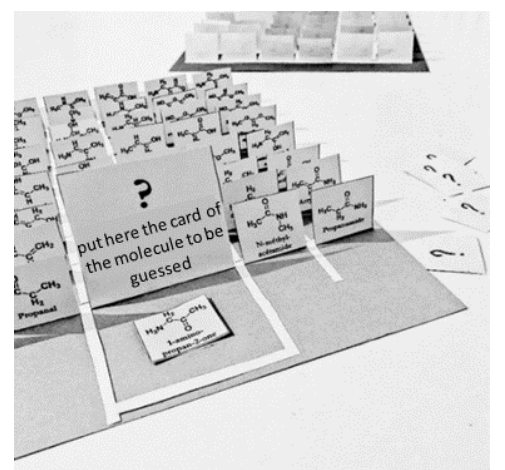

Figure 5: Board game - Who is it?

This activity allows all the notions that have been encountered in previous sessions to be taken up again. Indeed, to win a game, the pupil must ask his classmate about the characteristics of the molecule. He can ask his friend about the structure of the molecule, for example, "does the molecule have five carbon atoms?". Through this task, the pupils use the molecular formula, and more particularly the transition from the structural formula to the molecular formula and vice versa. In terms of registers, in this game pupils can also move from the oral register to the illustrated register and the algebraic register. It should be noted that many isomers have been chosen here (unlike in the Memory game) so that the winning strategies for the game are not limited to the determination of the molecular formula of the molecule.

Development of the tests

Pre-test

In the test given to the pupils each question is designed with a particular objective (Figure 6).

1 - What does the term "covalent bond" mean?

2- A covalent bond is formed between:

Two ions of the same charge.

Two ions of the opposite charge.

Two electrons.

Two protons.

Two neutrons.

Two atoms.

3- How do you represent a bond?

4- Within the covalent bond, the electrons:

Move.

Are immobile.

5- Draw the structure of the water molecule $\left(\mathrm{H}_{2} \mathrm{O}\right)$ in the following box.

6- The formula of the ethanol molecule is $\mathrm{C}_{2} \mathrm{H}_{6} \mathrm{O}$. What does this sentence mean?

Figure 6: Pre test about the representation of molecules

Question 1 is quite general, which allows a maximum amount of information about the pupils' initial conceptions to be collected. Indeed, the pupil is required to define the term "covalent bond". An expected response is (in 10 th Grade in France): the sharing of two external electrons by and between two atoms, each atom bringing an electron. It is therefore possible to compare pupil responses to the conceptions found in publications. In particular, we expect some pupils to bring out the concept that the bonds correspond to an interlocking of atoms. It is also possible to find the idea that the bond is between two electrons or that the bond is made only between two ions. The interest of this open 
question is therefore to compare the data in published works with the real conceptions of the pupils in the classes studied.

Similarly, the second question aims to gain an overview of the pupils' vision of the covalent bond. It should be noted that this is a multiple-choice question, which, contrary to the first question, proposes several misconceptions that the pupils might have, but that they would not think of writing in question one. This second question completes the first. The expected response is: two atoms.

Question 3 is about how a bond is depicted. In other words, this open question changes its register since it questions how a bond is represented and not, like the first two questions, the definition of a bond. In particular, it is intended to check whether the pupils have a materialist concept of the covalent bond, a conception found in publications.

The fourth question is multiple choice and targets another conception found in the published works: the position of the electrons within the covalent bond. Since the chapter on the electron shells of atoms has already been dealt with, all the pupils should have gone beyond the representation of immobile electrons. In view of our study object and the results provided by the publications, it seems relevant however to question this prerequisite.

Questions 5 and 6 measure the ease with which pupils move from one register to another without having worked on this skill in the context of the chemical bond. More specifically, the fifth question deals with the drawing of a molecule that they have been familiar with since high school, the water molecule, the molecular formula of which is given. The goal here is to see how the pupils represent the bond, without explicitly asking them to draw it. Moreover, the term of bonding does not appear in this question. It is therefore the passage from the molecular formula to the register of the schema. These registers are not those that are worked on in question 6 because the pupils are asked to proceed from the molecular formula to the written language register with the example of the ethanol molecule. These skills being worked on in the lesson plan studied, it seems appropriate to measure the pupils' evolution regarding this skill. For this reason, these questions, like all the pre-test questions, are also been asked in the post-test.

\section{Post-test}

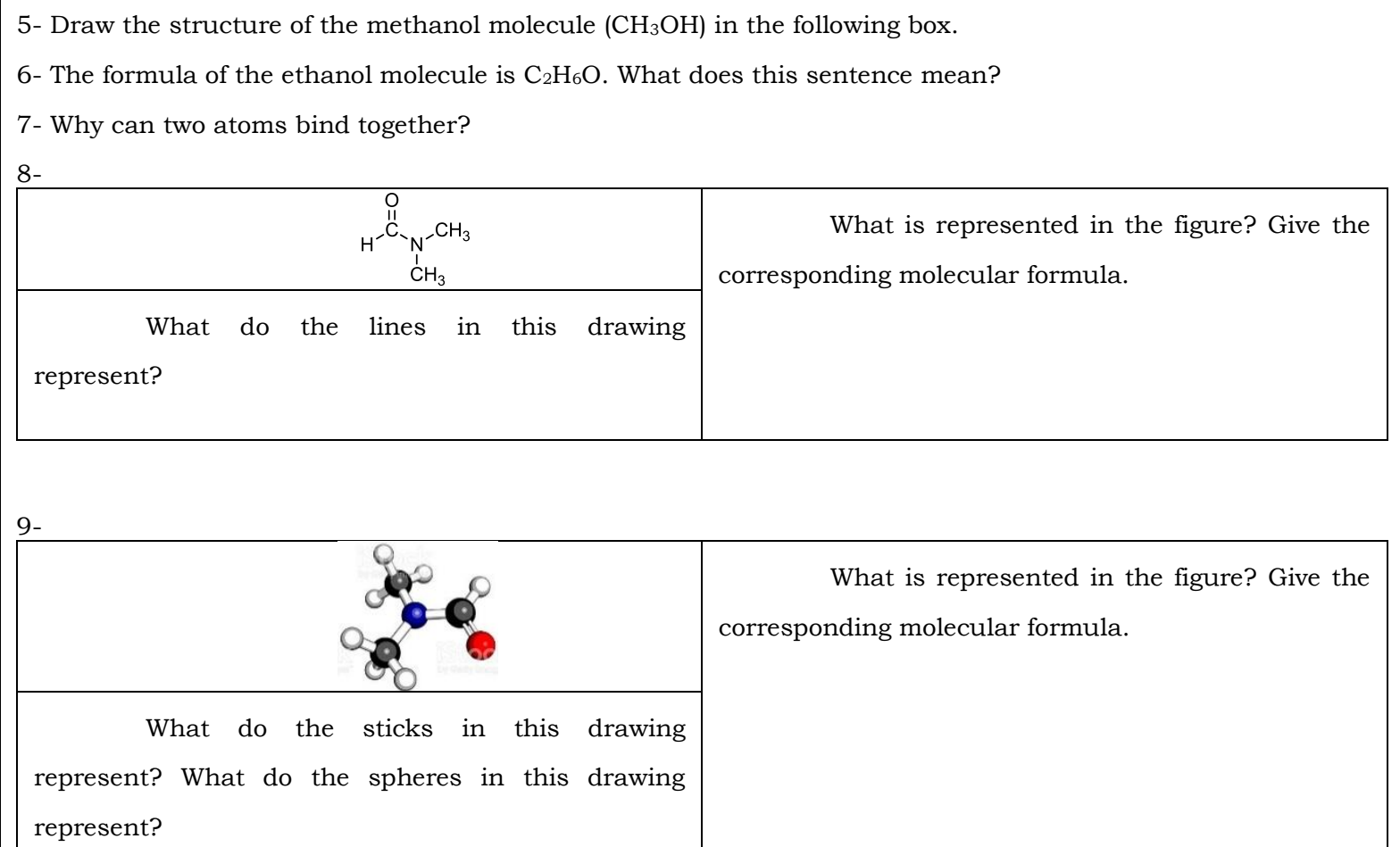

Figure 7: Post test about the representation of molecules 
All the pre-test questions were given in the post-test and the order of these questions was retained for the reasons explained in the previous section (Figure 7). The goal is to measure the effect of the session on the pupils' understanding but also to measure the evolution of their conceptions.

It is also interesting to note the change made to question 5 . The molecule that had been chosen in the pre-test was the water molecule, which pupils are familiar with since middle school. For the post test, the methanol molecule was chosen because it has a simple structure. The interest of this change is to check the pupils' understanding and not their ability to remember the pre-test.

It should be noted, however, that a question was inserted after question 6: "why can two atoms bind?" It aims to highlight anthropomorphic conceptions that would have persisted after the lessons but also an advanced understanding of chemical bonding.

Questions 8 and 9 are designed to bring out the link that the pupils make between different representations and registers. The order of these two questions aims to mobilize different registers for the pupils, starting with a structural formula and then, from a molecular model, two representations that were dealt with during the lessons.

\section{RESULTS AND DISCUSSION}

\section{Qualitative analysis: the board games}

The reports in which pupils explained their gaming techniques and transcribed class videos were analyzed. This task then allows, on the one hand, the effectiveness of the games to be assessed, that is to say whether they allow the notions and registers that we had planned as game strategies to be acquired, and on the other hand to highlight the pupils' misconceptions and difficulties.

\section{Memory}

When the pupils played "Memory", they set up some strategies to try and win the game. In particular, many explained, explicitly or not, by converting structural formulae into molecular formulae. In general, the pupils attempted to retain "the numbers of $H$ and $C$ atoms", as Vincent pointed out in his interview. Robin's strategy was particularly interesting: "It was difficult to remember the locations of the structural formulae, for that, I converted them into molecular formula to remember them more easily". Indeed, this pupil naturally modified the initial rules by making two piles of cards, one with the molecular formulae and the other with the semi-structural formulae. Thus, by first drawing the structural formula, Robin mentally converted it into a molecular formula and then found the associated card. It seems relevant to compare the strategies as they were explained by the pupils with the actual sequence of games during the sessions. To do this, transcripts of lesson recordings were studied. These are consistent with the pupils' reports. For example, the exchange between John and Adrien embodies well the conversion strategies of semi-structural formulae into molecular formulae:

"John - It's the same, oh no, because here I have four carbons and here I have only three

Adrien - Have to count them

John Jules - $\mathrm{C}_{3} \mathrm{H}_{6} \mathrm{O}_{2}$

Adrien - And that's $\mathrm{C}_{4} \mathrm{O}_{2} \mathrm{H}_{8}, \mathrm{C}_{4} \mathrm{O}_{2} \mathrm{H}_{4}$ no $\mathrm{C}_{4} \mathrm{O}_{2} \mathrm{H}_{8}$ and here what is it? $\mathrm{C}_{3} \mathrm{O}_{2} \mathrm{H}_{6}$ "

This exchange gives a good account of the transformation action of the structural formula into the molecular formula. Other pupils adopted the opposite strategy "We first looked at the semistructural formula and then we looked for the molecular formula that corresponds by looking at whether there are the right atoms and the right number". For these pupils, it was then necessary to "retain the number of bonds" of the semi-structural formulae since their strategy was to bring out the differences in the arrangement of the atoms within the molecules.

A last technique set up by many pupils was the search for heteroelements: "I concentrated on the "rare" or infrequent elements such as $\mathrm{Cl}, \mathrm{N}, \mathrm{O}$ ", "remember the molecules in which there are particular atoms $(\mathrm{N}, \mathrm{Cl} \ldots)$ ".

Finally, this game seems to have allowed the pupils to give meaning to the concepts of molecular, structural, semi-structural formulae but also to link these two objects. Moreover, in an analysis of the games, Chloe indicated that "Memory" is "very useful to learn to differentiate and make the connection between molecular and structural formulae".

Who is it? 
The game of "Who is it?" allows molecular and semi-structural formulae to be worked on. Here, in particular, the strategy of converting the semi-structural formula into molecular formula to ask one's opponent questions can be found, of which the phrases "I first converted structural formulae into molecular formula" and "first, I used molecular formulae to eliminate a number of molecules" are perfect examples. Indeed, all the pupils were trying to "ask questions about (...) the composition and the number of atoms", as stipulated by Jeanne in her notes. It is interesting to observe, however, that no pupil, who was filmed, asked the question "does the molecule have a molecular formula ...?" while many of them wrote down that they converted the structural formulae into molecular formulae. This observation can be justified by the fact that the card game was made up of many isomers. The molecular formula was not a sufficiently discriminatory element to progress in the game. However, the pupils used molecular formulae to question the presence of heteroatoms, as Louise explained in her examples of questions asked: "Does your molecule have a single oxygen atom?". Then, the pupils brought in other strategies to try to win the game. Among these, we can mention Fanny's, who "asked for the chemical functions" of the molecules. Hadrien explained that "we must use the chemical functions that eliminate a large number of molecules". In other words, this time it was possible to distinguish the various isomers through the characteristic groups they possess. However, since the name of the chemical functions is not known to $10^{\text {th }}$ Grade pupils, the latter expressed themselves rather in terms of groups of atoms "Do you have an $\mathrm{NH}_{2}$ in your formula?".

The most popular strategy used was based on the semi-structural formulae of the molecules. More precisely, the pupils focused their attention on the spatial arrangement of molecules and on the nature of the bonds. Anna said she asked her classmate, "Is there a single double bond in the molecule? For about half have one". Vincent and Louise agreed on the technique of "locating the different groups $\left(\mathrm{CH}_{3}, \mathrm{H}_{2}\right)$ " and then asked "are there two $\mathrm{CH}$ ?". It is this method that has been most commonly observed in the recordings.

\section{Happy Families}

The aim of the "Happy Families" game is to enable the pupils to construct a global vision of molecules using the different representations of these molecules. It seems that this objective has been achieved, at least in part, since this phrasing is found in some accounts. For example, Mathilde wrote that the game allowed her to "become familiar with the different forms of a molecule". Mathilde showed that this game made possible the attribution of meaning to the different representations. The strategy generally adopted was to analyze the cards in hand in order to determine which representations of the molecules were missing, in order to complete the families. Jeanne explained her approach as follows: "We proceed by elimination according to the cards we have". It seems that this strategy was unanimously used by the pupils in both classes.

In addition, one can also emphasize the fact that the majority of the pupils asked for the cards by naming the types of representation. However, some groups also relied on conversions between registers during the game, further promoting the construction of knowledge. For example, Lia did not ask for the molecular formula and the number of carbon atoms of the molecule with this vocabulary but questioned her classmate in the following way: "In the methane family, would you have $\mathrm{CH}_{4}$ ? (...) do you have four carbons?". During this didactical engineering, we were able to observe a great motivation and involvement of the pupils. One pupil even confided that these games reminded him of his childhood.

\section{Quantitative analysis: the tests}

\section{Pre- and post-test analysis}

We suggest that the pupils' manipulation of several semiotic registers should help them to construct the concept of different representations of molecules. In that respect we take a closer look at the answers to tests, focusing on first the pupils' answers to questions 5, 6, 8 and 9 of the postteaching sessions test. They concern the changes of registers. It may be observed that questions 8 and 9 are not discriminatory since all the pupils were able to convert a semi-structural formula into a molecular formula and a molecular model into a molecular formula.

The question 6 was designed to assess the pupils' ability to move from the illustrated register (molecular formula) to the written language register. Of course, it seems difficult to access the techniques set up by the pupils, but given the results of these questions, the didactical engineering 
used in class probably had a positive impact on their ability to move from one representation to another. To support this statement, we can notably mention the fact that, in the pre-test, fifteen pupils had given an incorrect answer to question 6 . The difference in the results between the two tests then shows the positive effect of the teaching sessions on the pupils' understanding. Indeed, both classes have reached the registry conversion.

In addition, for question 5, only five were unable to represent the structure of methanol. Of those who did, three pupils opted for a representation using a molecular model while the others represented it using a structural formula. As an element of comparison, we can recall that, in the pretest, eleven pupils failed to draw the structure of the water molecule. Of these, only one has not progressed. The other four who gave wrong answers in the post-test were able to represent the water molecule in the pre-test. It is therefore interesting to re-examine their exam paper to find out if it was a recurrent problem or a mistake that could be described as carelessness. For two of them, no error of this type had been made during the classroom assessment, which would tend to confirm that it was a mistake due to carelessness. On the other hand, for the last pupil, we note that these mistakes are also visible in his test paper. Thus, it would seem that the proposed teaching sessions allowed ten pupils to overcome the obstacle of moving from one representation to another, but that one out of sixty-nine pupils did not manage to overcome this difficulty.

Representation conversion activities were designed to improve the pupils' understanding of the concept of bonding. Indeed, we suggested that situations based on board games favored the construction of this concept. It would therefore be interesting to assess if these didactic tools have had a noticeable effect on pupil learning. For this purpose, the answers to questions 1, 2, 3, 4 and 5 of the post-test were analyzed in light of the pre-test ones (Table 1).

It should be noted that 68 out 69 pupils questioned were able to represent the covalent chemical bond by a line, according to the formalism reviewed during the teaching sessions, whereas fifty-nine pupils gave an erroneous representation during the pre-test (Q3). It therefore seems that the proposed teaching sessions have allowed the formalism linked to the chemical bond to be constructed. This result is rather encouraging.

To complete this initial analysis of the understanding of the concept of bonding, we also focused on the meaning the pupils attributed to the term "covalent bond" and the physical interpretation they made of it (Q1). We then note that fifty-seven gave a correct vision of the covalent bond. It is interesting to note, however, that these pupils did not necessarily share the same vision:

- Thirty-three of them referred to the definition of bonding, as it was written down in their course work: it is the sharing of electrons.

- Nine referred to the actors of the bonding: the bond is between two atoms.

- Ten others evoked the notion of the saturation of the valence layer, which already suggests that the physical phenomenon is being partially interpreted.

$500-$ Similarly, five pupils talked of stabilizing the atoms that form the bond, which is also part of the physical interpretation.

On the other hand, twelve pupils had difficulty in constructing the concept of the covalent bond. For example, one brought out the materialistic misconception by stating that the bonding "is an electron bond". This conception was also identified during an exchange between the pupils during a group activity, which may explain the persistence of this preconceived idea: " $a$ bond is the fact that they are hooked together". Others used the term electron exchange or bonding between electrons, terminologies that do not correspond to the notion of covalent chemical bonding. Forty-two pupils were in the same situation during the pre-test. In view of these results, one would expect to have two pupil profiles: the fifty-seven who constructed the notion of bonding and the twelve others who still have misconceptions about it.

Yet the pupils' answers to the post-test questions did not follow that logic. In fact, when they were asked to say between which entities the bond occurs (Q2), among the fifty-seven who gave the correct meaning, ten stated that the bonding is between electrons and not between atoms. These pupils therefore have a partial understanding of the concept of chemical bonding. It is possible to tone down this last statement since the question that followed this one in the post-test was "are the electrons within the bond immobile or moving?" which could have thrown the pupils off track. In addition, of the twelve who gave an erroneous definition of the chemical bond, five of them indicated that the bond is between two atoms and seven answered that it is between two electrons, which shows 
that certain conceptions persist even after the teaching. Therefore, it seems that the border dividing the pupils who built the concept of bonding and those who did not is not clearly defined. There is, however, a group of pupils who have difficulties in overcoming their misconceptions, a group of those who have grasped the notion of bonding and a group for whom this notion is still in the process of being acquired. These results can be found in the answers to the question "are the electrons within the bond immobile or moving?" where fifty-eight pupils answered that the electrons were moving. Only eleven pupils gave an incorrect answer, among whom are five who showed an advanced understanding of the covalent bonding concept, five who had a partial understanding of this concept and one who did not succeed in constructing this notion. ${ }^{33}$

\begin{tabular}{ccc} 
Table 1: Comparison of correct responses between pre-test and post-test \\
Questions & Pre test & Post test \\
Q1 & $27 / 69(39.1 \%)$ & $57 / 69(82.6 \%)$ \\
Q2 & $35 / 69(50.7 \%)$ & $50 / 69(72.5 \%)$ \\
Q3 & $10 / 69(14.5 \%)$ & $68 / 69(98.5 \%)$ \\
Q4 & $39 / 69(56.5 \%)$ & $58 / 69(84.1 \%)$ \\
Q5 & $58 / 69(84.1 \%)$ & $64 / 69(92.8 \%)$ \\
Q6 & $54 / 69(78.3 \%)$ & $69 / 69(100 \%)$ \\
\hline
\end{tabular}

530

To complete the analysis on understanding the concept of bonding, we looked at the pupils' interpretation of the covalent bonding phenomenon (Q7). There are fourteen who were not able to give a coherent interpretation of the bonding. Of these, two had already shown a distorted view of the concept of bonds in their answers to previous questions, five had only partially understood, and seven had advanced understanding. This last result seems surprising. One possible explanation is that since these pupils had already proposed an interpretation of the bond in their answer to the question "what does the term chemical bond mean?" the new question may have seemed redundant and they did not know how to respond differently.

\section{Comparison with the control class}

In order to discuss the effectiveness of the proposed teaching plan, it seems relevant to compare the results of the two classes that followed it with a control class in which was given a more traditional approach (Table 2). It should be noted that the control class had substantially the same pre-test results level as the pupils in the two classes in this study, which allows the evolution of each class to be visualized more clearly (56\% correct answers for the control class versus 54\% correct answers for the tested classes). There were 34 pupils in the control class.

Comparative analysis of post-test responses shows that for both pupil samples, the proportion of the pupils who think the covalent bond is between two electrons is about the same. For the analysis to be more visible, the proportions are given as percentages since the starting numbers were different. Thus, it is estimated that $24 \%-26 \%$ of the pupils have retained this misconception (Q2). In addition, we find the same proportions, namely $100 \%$, for those who represent the chemical bond by a line (Q5). These questions are therefore not discriminatory. It can therefore be concluded that the proposed lesson plan has no major impact on the learning of the representation of molecules and the notion of bonding itself.

Some answers, however, reveal learning differences. Indeed, for the control class, $59 \%$ of the pupils think that the electrons are immobile within the covalent bond while this percentage is low $(16 \%)$ in the classes tested, which seems to indicate that pupils in the test-case classes have gained some knowledge of the chemical bonding model $\left(\chi^{2}=19.9\right)$. As far as register conversions are concerned, it is clear that this type of process was more difficult in the control class since there are $9 \%$ mistakes in these conversions whereas there are only 3\% in the test classes (Q5 and Q6).

Finally, when the pupils are asked about the physical interpretation of the covalent bond (Q7), that is the sharing of electrons, $80 \%$ of those in the tested classes provide a correct interpretation, compared to $18 \%$ in the control class $\left(\chi^{2}=36.32\right)$. In view of these results, it would seem that the teaching provided has favored a more comprehensive construction of the concept of chemical bonding. The whole of this analysis is summed up in the table below (table 2). 
Table 2: Comparison of post test responses between control class and tested ones.

\begin{tabular}{rccc}
$\begin{array}{l}\text { Post test } \\
\text { questions }\end{array}$ & Control class & Tested classes & $\chi^{2}$ \\
Q1 & $38 \%$ & $82.6 \%$ & 20.6 \\
Q2 & $71 \%$ & $72.5 \%$ & Not significant \\
& $(24 \%$ answer & $(26 \%$ answer & \\
Q3 & $100 \%$ & between electrons $)$ & Not significant \\
Q4 & $41 \%$ & $98.5 \%$ & 19.9 \\
Q5 & $88 \%$ & $84.1 \%$ & Not significant \\
Q6 & $94 \%$ & $92.8 \%$ & Not significant \\
Q7 & $18 \%$ & $100 \%$ & 36.3 \\
\hline
\end{tabular}

\section{Analysis of the 11th Grade test}

In addition to the comparison with the control class in $10^{\text {th }}$ Grade, the year after, the pupils in the same high school, now in $11^{\text {th }}$ Grade, were given a test on the bonding and representation of the molecules (three classes, see methodology). Among the pupils interviewed, some had followed the previous year's "games" sessions. Thus, the presence of these two types of populations allowed us to measure the effectiveness of this teaching plan in terms of mobilized semiotic registers.

This test took place after the session on Lewis' representation. In the test, questions about this representation were asked as well as questions about covalent bonding and the representation of molecules. We are only interested here in the questions about the covalent bonding and the representation of molecules.

The answers in this test show that, overall, the pupils who had followed the "games" sessions the previous year get better results, the percentage of right answers is higher. Some significant items regarding our central argument are analyzed.

Q1: What is a "covalent bonding"? Give a definition.

For the question on the definition of the covalent bond, $46 \%$ of the pupils who followed the "games" sessions gave a correct definition, compared to $19 \%$ for the other pupils (with a $\chi^{2}=6.1$ ).

Q2 : see Figure 8

\begin{tabular}{|c|l|}
\hline & \multicolumn{1}{|c|}{ What is represented in the drawing? Give the } \\
& corresponding formula. \\
\hline
\end{tabular}

What do the lines in the drawing represent?

Figure 8: Question 2 of the $11^{\text {th }}$ Grade test

The purpose of question 2 is to get the pupils to use different registers to move from a semistructural formula to the corresponding molecular formula. Of those who followed the "games", 92\% gave a correct answer compared to $81 \%$ for those who did not follow them.

Q3: Is the representation of the bond in Question 2 flawed or imprecise? If so explain.

Question 3 should show if the pupils have acquired a deeper knowledge of the different representations. The main flaws mentioned are that, on a structural or semi-structural formula, it is not possible to see the lone pair nor the geometry. $36 \%$ of the pupils who did not follow the "games" did not point to any flaws against $12.5 \%$ of those who had followed it $\left(\chi^{2}=4.6\right)$. In addition, this open question allows the pupils to give several possible answers. We also find a great variety of answers among the pupils who had followed the "games sessions" since 38\% among them gave more than one criterion against $10 \%$ among those not having followed it $\left(\chi^{2}=8.4\right)$.

Q4: Why can two atoms bond?

This question is used to see if the pupils have understood the concept of covalent bonding. It completes the first item of this test. Here again, students who had taken didactical engineering in the previous year answered this question better (83.3\% versus $65.5 \%$, which is not significant). 
Table 3: Comparison between pupils who have followed the "game" session and pupils who have not.

\begin{tabular}{llll}
\multicolumn{1}{c}{ Statement } & \multicolumn{1}{c}{$\begin{array}{c}\text { "games" pupils } \\
(\mathrm{N}=24)\end{array}$} & \multicolumn{1}{c}{$\begin{array}{c}\text { Control pupil } \\
(\mathrm{N}=58)\end{array}$} & \multicolumn{1}{c}{$\chi^{2}$} \\
Q1 & $46 \%(11$ pupils $)$ & $19 \%(11$ pupils $)$ & 6.1 (significant) \\
Q2 & $92 \%(22$ pupils $)$ & $81 \%(47$ pupils $)$ & 1.4 (not significant) \\
Q3 & $12.5 \%(3$ pupils $)$ & $36 \%(21$ pupils $)$ & 4.6 (significant) \\
Q3 Variety of answers & $38 \%(9$ pupils) & $10 \%(6$ pupils $)$ & 8.4 (significant) \\
Q4 & $83.3 \%$ (20 pupils) & $65.5 \%(38$ pupils) & 2.7 (not significant) \\
\hline
\end{tabular}

Return on the misconceptions and difficulties of pupils

In addition to a better understanding of the concept of covalent bonding and representation of molecules, we look at whether didactical engineering has had any effect on some of the misconceptions we listed at the beginning.

- Materialist conception: During the pre-test in the first question (definition of covalent bond), some pupils used the word "attachment" to define a bond. We did not find this term in the post test.

- Electron/ion confusion: In the multiple-choice question 2, some pupils answered that a covalent bond was formed between two ions (of opposite charges or of the same charge). In the post test, we hardly found this proposition anymore (only the answer between atom or between electrons). table 1).

- Electron immobility: the conception of electron immobility in a bond strongly decreased (see

- Personification: In the question on "why can two atoms bind together", there were anthropomorphic answers such as "need", "want" in the pre-test; they disappeared in the post-test. learning.

Therefore, we can conclude that the didactical engineering has a positive effect on the pupils'

\section{CONCLUSION}

This work focused on the understanding and learning difficulties associated with representations of molecules and chemical bonding in $10^{\text {th }}$ Grade. The approach that was followed was to examine the connection between a teaching plan and pupil learning. On the one hand, an analysis of the pupils' misconceptions was carried out in published works. On the other hand, a lesson plan (didactical engineering) was developed, based on the mobilization of several semiotic registers, in order to understand to what extent these didactic choices have an impact on how $10^{\text {th }}$ Grade pupils grasp and retain the bonding concept.

The aim of this work was to understand if mobilizing several semiotic registers in situations like games could promote the learning of the concept of chemical bonding. It would seem that pupils are more comfortable with the concepts studied in learning situations that encourage their involvement. Moreover, the mobilization of several semiotic registers would allow a more global concept to be constructed. Moving from a molecular formula to a structural formula, to a definition, to a schema, to a calculation of the number of atoms, mobilizes these registers, which leads to a better understanding of the concept. This study has made a number of contributions to the initial problem. In particular, it shows how the results obtained can be used to validate research hypotheses. The purpose is to discuss the effectiveness of the instructional intervention.

The approach mobilizing several semiotic registers seems to have allowed a physical meaning to be attributed to the concept of bonding through several types of representation, favoring reasoning based on internal and external conversions to the registers. Indeed, in group activities, the pupils regularly progressed from the common, oral register to the written language register when taking down notes for the course-work, but also from the register illustrated in the numerical register during the study of representations of molecules. In addition, the internal conversions are mainly carried out in the illustrated register, during the transition from molecular models to structural, semi-structural and molecular formulae.

The pupils' results, during the post-test, show that they are able to move easily from one register to another. In addition, the mobilization of several registers seems to have contributed to the construction of a more global vision of the concept of bonding. In comparison, the control class pupils, for whom registry conversions seemed more difficult, are more likely not to have constructed the 
concept of bonding as a whole. It is important to emphasize that it is not necessary to mobilize all the semiotic registers if they do not lend themselves to acquisition of the intended knowledge, which was the case of the formal register, which was quickly removed from the study.

Thus, these games facilitate the mobilization of knowledge and the skills to be acquired without their having to be explained. In addition, this project shows how traditional board games can be adapted for teaching purposes. In particular, the latter have been designed so that winning strategies require semiotic registers. They have proved particularly useful in assimilating the concept of chemical bonding: "Memory", "Happy Families" and "Who is it"? have involved the pupils in register conversion strategies that allow for the construction of bonding notions, molecule representation, model and chemical function. The analysis of the " $11^{\text {th }}$ Grade" tests one year later confirms the effectiveness of this didactical engineering. The use of several registers seems to facilitate the learning of the covalent bond through several types of representations.

Limitation of the study and implications

As is the case with case study, the small sample size limits the generalizability of the results. It is indeed difficult to generalize, at this stage, to the whole population of the same age. Nevertheless, the results are relevant and this study case has the potential to inform instruction and future research in this area.

This research has implications for both the chemistry classroom and future education research studies. The games described here could indeed be used for other notions (for example organic functions...). Either the same games are adapted for another notion or other games are envisaged for other notions such as "snakes and ladders". It is therefore necessary to think carefully about the notion that one wants to study with games because it may be inconceivable to do several sessions of this kind, in the sense that it is time-consuming. In addition, they allow to mobilize several semiotic registers that lead to a global understanding of a concept. Future research studies should further explore the use of such games in chemistry courses. As we have seen, this kind of study has helped to overcome some misconceptions.

\section{ASSOCIATED CONTENT}

Supporting Information

The Supporting Information is available on the ACS Publications website at DOI:

10.1021/acs.jchemed.XXXXXXX. [ACS will fill this in.] Rules of the games (docx).

\section{AUTHOR INFORMATION}

*E-mail: karine.molvinger-verger@umontpellier.fr

\section{ACKNOWLEDGMENTS}

The authors thank the teachers who participated in this study: Mrs Le Men and Mrs Ponnou. We

thank Mrs Di Miceli for her proofreading of the article.

\section{REFERENCES}

1. Lafarge, D. Analyse didactique de l'enseignement-apprentissage de la chimie organique jusqu'à bac +2 pour envisager sa restructuration. Education. Université Blaise Pascal - Clermont-Ferrand II, 2010.

2. Hiberty, P.; Nguyen, T. A. Introduction à la chimie quantique, Ecole Polytechnique, 2008.

3. Chaquin, P.; Volatron, F. Chimie organique : une approche orbitalaire, De Boeck Superieur, 2015. 
4. Taber, K. S. Conceptualizing quanta: illuminating the ground state of student understanding of atomic orbitals, Chem. Educ. Res. Pract., 2002, 3, 145-158.

5. Lautier, G. Etude des pratiques enseignantes en CPGE dans le cadre du passage du modèle classique au modèle orbitalaire en réactivité organique. Université de Montpellier, 2017.

6. French Education Ministry (France), Programme de Physique-chimie en classe de seconde générale et technologique. Bulletin officiel de l’Éducation nationale, spécial nº 18 du 4 Mai 2017.

7. In the semi-structural formula (also called condensed structural formula), covalent bonds are not always shown and atoms of the same type bonded to one another are grouped together. For example, for pentane, the semi-structural formula is $\left(\mathrm{CH}_{3}\right)\left(\mathrm{CH}_{2}\right)_{3}\left(\mathrm{CH}_{3}\right)$.

8. Taber, K. S. An alternative conceptual framework from chemistry education, Int. J. Sci. Educ., 1998, 20 (5), 597-608.

9. Wightman, T.; Green, P.; Scott, P. The Construction of Meaning and Conceptual Change in Classroom Settings: Case Studies on the Particulate Nature of Matter, Leeds: Centre for Studies in Science and Mathematics Education, University of Leeds, 1986.

10. Unal, S.; Calik, M.; Ayas, A.; Coll, R. K. A review of chemical bonding studies : needs, aims, methods of exploring students' conceptions, general knowledge claims and students' alternative conceptions, Res. Sci. Technol. Educ., 2006, 24 (2), 141-172.

11. Peterson, R. F.; Treagust, D. F. Grade-12 students' misconceptions of covalent bonding, J. Chem. Educ., 1989, 66 (6), 459-460.

12. Robinson, W. R. An alternative framework for chemical bonding, J. Chem. Educ., 1998, 75 (9), 1074-1075.

13. Ducamp, C.; Rabier, A. L'enseignement du modèle de Lewis de la liaison covalente au lycée, Union des professeurs de physique et de chimie, BUP 969, 2014, 108, 1515-1542.

14. Tsaparlis, G.; Pappa, E.T.; Byers, B. Teaching and learning chemical bonding: research-based evidence for misconceptions and conceptual difficulties experienced by students in upper secondary schools and the effect of an enriched text, Chem. Educ. Res. Pract., 2018, 19, 12531269.

15. Taber, K. S.; Watts, M. The secret life of the chemical bond: students' anthropomorphic and animistic references to bonding, Int. J. Sci. Educ., 1996, 18 (5), 557-568.

16. Duval, R. Registres de représentation sémiotique et fonctionnement cognitif de la pensée. Annales de didactique et de sciences cognitives, 1993, 5 (1), 37-65.

17. Duval, R. A cognitive analysis of problems of comprehension in a learning of mathematics. Educational Studies in Mathematics, 2006, 61, 103-131.

18. Duval, R. Sémiosis et pensée humaine: registres sémiotiques et apprentissages intellectuels. Berne: Peter Lang, 1995. 
19. Malonga Moungabio, F.; Beaufils, D. Modélisation et registres sémiotiques : exemple d'étude de manuels de physique de terminale. Recherches en didactique des sciences et des technologies, 2010, 1, 293-316.

20. Mc Gee, D.; Martinez-Planell, R. A Study of semiotic registers in the development of the definite integral of functions of two and three variables, International Journal of Science and Mathematics Education, 2014, 12 (4), 883-916.

21. Artigue, M. Perspectives on design research: the case of didactical engineering. Angelika BiknerAhsbahs; Christine Knipping; Norma Presmeg. Approaches to qualitative research in mathematics education, Springer, 2014, pp 467-496.

22. Canac, S; Kermen, I. Exploring the mastery of French students in using basic notions of the language of chemistry, Chem. Educ. Res. Pract., 2016, 17, 452-473.

23. It is important to note that "didactical engineering" is quite different of "action research", which is a philosophy and methodology of research generally applied in the social sciences. It seeks transformative change through the simultaneous process of taking action and doing research, which are linked together by critical reflection. Design-based research (DBR) is a type of research methodology used by researchers in the learning sciences, which is a sub-field of education. The basic process of DBR involves developing solutions (called "interventions") to problems. Then, the interventions are put to use to test how well they work. These three methodologies are similar but they are not used in the same disciplines; didactical engineering is used in didactics of mathematics and science while the others are more used in educational science.

24. Artigue, M. Ingénierie didactique. Recherche en didactique des mathématiques, 1989, 9 (3), 281 308. (English translation: Artigue, M. Didactical engineering. In: Douady R, Mercier A (eds) Recherches en Didactique des Mathématiques, Selected papers, 1992, pp 41-70).

25. Artigue, M. Didactical engineering as a framework for the conception of teaching products, In R. Bielher, R.W. Scholz, R. Straesser, B. Winkelmann (Eds.), Didactics of Mathematics as a Scientific Discipline, 27-39. Dordrecht: Kluwer Academic Publishers, 1994.

26. Brousseau, G. Theory of didactical situations in mathematics. Kluwer Academic Publishers, 1997.

27. Artigue, M. Didactical engineering. In: Douady R, Mercier A (eds) Recherches en Didactique des Mathématiques, Selected papers, 1992, pp 41-70.

28. Margolinas, C., Drijvers, P. Didactical engineering in France; an insider's and an outsider's view on its foundations, its practice and its impact. ZDM The international Journal on Mathematics Education, 2015, 47, 6, 893-903.

29. De Hosson C.; Decamp N. Using Ancient Chinese and Greek Astronomical Data: A Training Sequence in Elementary Astronomy for Pre-Service Primary School Teachers, Sci. Educ., 2014, 23(4), 809-827. 
30. A situation is a-didactical if the teacher's specific intentions are successfully hidden from the students and the student can function without the teacher's intervention.

31. Warfield, V. M. Invitation to Didactique, University of Washington, 2006.

32. This master is called "Master in Didactics of Science"

33. We call "advanced understanding" students who answered correctly to the three previous questions, "partial understanding" students who answered incorrectly to one of the previous questions. 